\title{
Evaluasi Geometri Jalan Menggunakan UAV Dengan Aplikasi Agisoft Photoscanner Pada Jalan Meranti Kampus IPB Dramaga
}

\section{(Road Geometry Evaluation Using UAV with Agisoft Photoscanner in Meranti Street Dramaga IPB University)}

\author{
Dhia Kamal Irfan ${ }^{1}$, Sutoyo $^{2 *}$, Tri Sudibyo ${ }^{3}$ \\ ${ }^{1}$ Departemen Teknik Sipil dan Lingkungan, Fakultas Teknologi Pertanian, Institut Pertanian Bogor. \\ Jl. Raya Dramaga, Kampus IPB Dramaga, PO BOX 220, Bogor, Jawa Barat Indonesia \\ *Penulis Korespondensi: sutoyo@apps.ipb.ac.id
}

\begin{abstract}
There are various road construction projects in Indonesia, but most of these projects still use conventional methods in evaluating road geometry. This study aims to evaluate the geometry of the road using UAV and analyze the accuracy and accuracy of photogrammetry in the evaluation of road geometry. This research took place at Dramaga's IPB Campus on Meranti street and was conducted from April to July 2019. From a series of processes that have been carried out it can produce accuracy of measuring 97,243\% and 98,296\% across the road for orthophoto results without and with coordinate correction and using GCP. For accuracy in this study obtained a value of $0.858 \mathrm{~m}$ so that it can be concluded that the data processing map is included in the class 3 horizontal accuracy. The horizontal alignment parameters analyzed in this study are bend angles, turn radius, and turn length, there are two curves analyzed. For the value of each parameter each turn successively for data without coordinate correction and elevation is 149 $\circ$; $90^{\circ} ; 40.61 \mathrm{~m} ; 53.75 \mathrm{~m} ; 23.39 \mathrm{~m} ; 90.71 \mathrm{~m}$. The results of horizontal alignment analysis for data with coordinate correction are $150^{\circ} ; 88^{\circ} ; 30.81 \mathrm{~m} ; 49.34 \mathrm{~m} ; 21.39 \mathrm{~m} ; 89.3 \mathrm{~m}$. The vertical alignment analyzed in this study has two parameters, namely vertical curvature and slope. The value of the analysis results for the two parameters of the two points for results with correction and without correction of coordinates are $16.08 \%, 17.22 \%, 53 \mathrm{~m}, 51 \mathrm{~m}$ and $6.88 \%, 3.77 \%, 53 \mathrm{~m}$, and $51 \mathrm{~m}$.
\end{abstract}

Keywords: horizontal alignment, orthophoto, road geometry, UAV, vertical alignment

\section{PENDAHULUAN}

Pembangunan infrastruktur jalan yang ada di Indonesia akhir akhir ini semakin banyak karena masalah kemacetan dan kebutuhan akan peningkatan ekonomi yang semakin lama semakin meningkat. Makin tinggi arus lalu lintas, semakin besar dimensi yang diperlukan (Koloway 2009). Menurut El-Reedy (2011), menyatakan bahwa proses pembangunan proyek konstruksi terdiri dari tujuh tahapan, tahapan-tahapan tersebut adalah ide, studi kelayakan, pra desain, detail engineering design, pengadaan atau pelelangan, pelaksanaan atau konstruksi, serta operasional dan pemeliharaan. Dari ketujuh tahapan tersebut terdapat beberapa faktor yang mempengaruhi kesuksesan suatu proyek konstruksi jalan. Menurut Gunawan dan Afifuddin (2014), terdapat 10 faktor yakni kemampuan menyelesaikan masalah, sistem komunikasi, efektifitas membuat keputusan, penekanan owner pada mutu tinggi konstruksi, monitoring proyek, keahlian memimpin manager proyek, kemampuan teknik manajer proyek, penekanan owner pada konstruksi yang cepat, manajemen proyek owner, dan kecukupan dana. 
JSIL | Irfan dkk. : Evaluasi Geometri jalan Menggunakan UAV Dengan Aplikasi Agisoft Photoscanner Pada Jalan Meranti Kampus IPB Dramaga

Perkembangan teknologi saat ini sangat lah pesat. Banyak teknologi baru lahir dan berkembang untuk membantu meringankan dan mempermudah kerja manusia dengan berbagai fitur-fitur di dalamnya. Salah satunya adalah unmanned aerial vehicle (UAV) atau sering disebut dengan drone yang merupakan pesawat tanpa awak di dalamnya. Peralatan UAV ini bergerak otomatis sesuai dengan program yang tertanam pada sistem komputer dan dikendalikan dari jarak jauh dengan menggunakan remote control dari luar kendaraan atau disebut dengan remotely piloted vehicle (RPV) (Nugroho 2016).

Saat ini UAV berkembang sangat cepat tak hanya untuk militer saja akan tetapi dapat digunakan untuk kehidupan sehari-hari, diantaranya: penginderaan jarak jauh, melakukan respon terhadap bencana yang terjadi, patroli keamanan dan lalu lintas, membawa dan mengirimkan barang, melakukan pengambilan gambar, hingga memantau proses konstruksi yang sedang berjalan. Penggunaan UAV atau drone untuk memantau proses konstruksi ini merupakan inovasi baru bagi dunia konstruksi. Pasalnya, hampir keseluruhan proyek konstruksi mengandalkan tenaga manusia untuk melakukan pengawasan dan pemantauan proses konstruksi. Penelitian ini dilakukan pada Jalan Meranti Kampus Institut Pertanian Bogor Dramaga. Berdasarkan latar belakang tersebut dapat dirumuskan permasalahan pada penelitian ini adalah bagaimana pemanfaatan UAV untuk mengevaluasi geometri jalan dan tingkat akurasi data fotogrametrinya. Sedangkan tujuan dilaksanakannya penelitian ini adalah melakukan evaluasi geometri jalan menggunakan UAV serta analisis tingkat akurasi dan ketelitian fotogrametri dalam evaluasi geometri jalan.

\section{METODOLOGI}

Penelitian ini dilaksanakan mulai April 2019 hingga Juli 2019. Pengambilan data primer akan dilakukan pada lokasi penelitian, yaitu Jalan Meranti Kampus IPB Dramaga. Pengolahan dan analisis data dilakukan secara intensif di Departemen Teknik Sipil dan Lingkungan, Fakultas Teknologi Pertanian, Institut Pertanian Bogor. Gambar lokasi penelitian diambil menggunakan aplikasi google earth. Lokasi penelitian dapat dilihat pada Gambar 1.

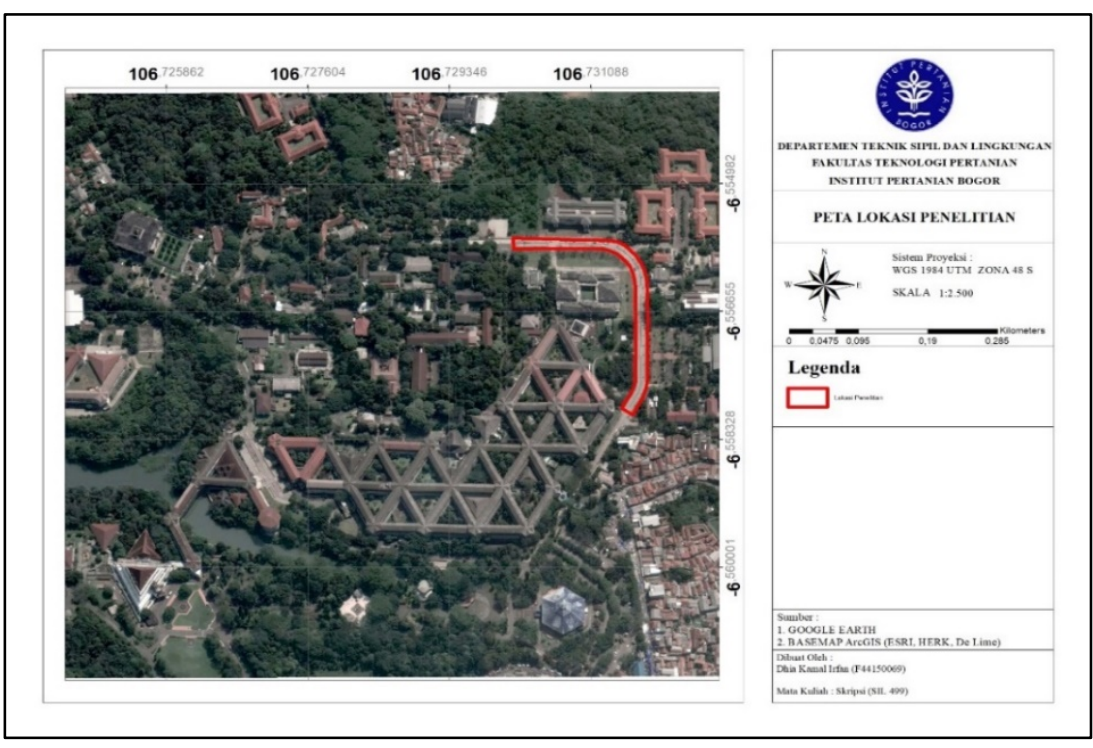

Gambar 1 Lokasi penelitian 
Alat yang digunakan dalam penelitian ini adalah sebuah multi rotor UAV berupa drone dengan merek Xiaomi Mi Drone 4K dengan maksimum resolusi 4000x3000 piksel, seperangkat total station, roll meter, seperangkat komputer yang dilengkapi dengan program microsoft office, arcGIS, agisoft photoscanner, dan agisoft Lens. Bahan yang digunakan dalam penelitian ini terbagi menjadi dua data yakni data primer berupa fotogrametri Jalan Meranti Kampus IPB Dramaga dengan menggunakan multi rotor UAV berupa drone, lebar jalan, dan koordinat serta elevasi dari titik kontrol tanah (GCP) sedangkan dan data sekunder yang diperoleh dari Badan Informasi Geospasial berupa detail titik kontrol geodesi nasional (TKG).

Tahapan pertama dari penelitian ini adalah studi literatur mengenai metode yang akan digunakan serta perangkat lunak yang akan digunakan, kemudian kalibrasi kamera yang akan digunakan menggunakan aplikasi agisoft lens. Data yang diperlukan adalah data primer berupa fotogrametri Jalan Meranti Kampus IPB Dramaga 1 menggunakan multi rotor UAV (drone), lebar jalan, dan koordinat serta elevasi dari titik kontrol tanah (GCP) sedangkan data sekunder berupa detail titik kontrol geodesi nasional (TKG). Kemudian, hasil yang didapatkan dari multi rotor UAV berupa drone diolah menggunakan agisoft photoscanner sehingga didapatkan data model elevasi digital (DEM). Setelah didapatkan data DEM dari olahan drone maka data DEM yang didapatkan menggunakan drone dibandingkan dengan data DEM yang didapat setelah melakukan pengohalan data elevesai yang didapatkan dari total station sehingga dapat terlihat perbedaan atau kesamaan dari elevasi yang didapatkan dari citra drone dengan realisasi. Untuk hasil foto udara yang telah dilakukan bisa dibandingkan juga dengan lebar jalan sehingga dapat terlihat perbandingan antara citra drone dan realisasi di lapang.

Data yang digunakan dalam penelitian adalah data primer berupa foto Jalan Meranti Kampus IPB Dramaga menggunakan drone kemudian diolah menggunakan software agisoft photoscanner dan arcGIS, selain foto udara data primer yang diambil berupa lebar jalan dan elevasi dari titik kontrol tanah (GCP). Sebelum data primer diambil terlebih dahulu kamera drone dikalibrasi dengan agisoft lens. Data sekunder berupa detail dari titik kontrol geodesi nasional (TKG) yang kemudian di gunakan sebagai acuan koordinat titik kontrol tanah (GCP). Untuk data primer dilakukan pengambilan pada Jalan Meranti Kampus IPB Dramaga sedangkan data sekunder diperoleh dari Badan Informasi Geospasial (BIG).

\section{HASIL DAN PEMBAHASAN}

Gambar 2 merupakan persebaran titik kontrol yang dilakukan untuk mengetahui koordinat dari titik ground control point atau titik kontrol tanah yang dipasang pada lokasi penelitian. Koordinat ini didapatkan dengan mengacu pada titik kontrol geodesi nasional yang berada $\pm 1,5 \mathrm{Km}$ dari titik gcp pertama atau lokasi penelitian. Detail dari titik kontrol geodesi nasional yang diacu dapat dilihat pada Tabel 1 .

Dari Tabel 1 dapat dilihat koordinat dari titik kontrol geodesi nasional yang diacu adalah 6³3'46.50480" LS dan 10643'22.46160" BT. Titik kontrol yang sudah diketahui koordinatnya kemudian dijadikan acuan untuk menentukan koordinat GCP yang berada pada lokasi penelitian. Jarak dari titik kontrol geodesi nasional dan GCP yang cukup jauh memerlukan beberapa titik 
JSIL | Irfan dkk. : Evaluasi Geometri jalan Menggunakan UAV Dengan Aplikasi Agisoft Photoscanner Pada Jalan Meranti Kampus IPB Dramaga

bantuan untuk mencapai GCP yang telah ditentukan sebelumnya. Maka dari itu pada penelitian ini diambil 12 titik bantu, 5 titik bantu berada di luar kampus IPB Dramaga dan 7 titik berada di dalam kampus IPB Dramaga seperti yang dapat dilihat pada Gambar 2. Koordinat titik bantu ini diambil menggunakan total station dengan metode polygon terbuka. Sedangkan GCP yang digunakan pada penelitian ini dapat dilihat pada Gambar 3.

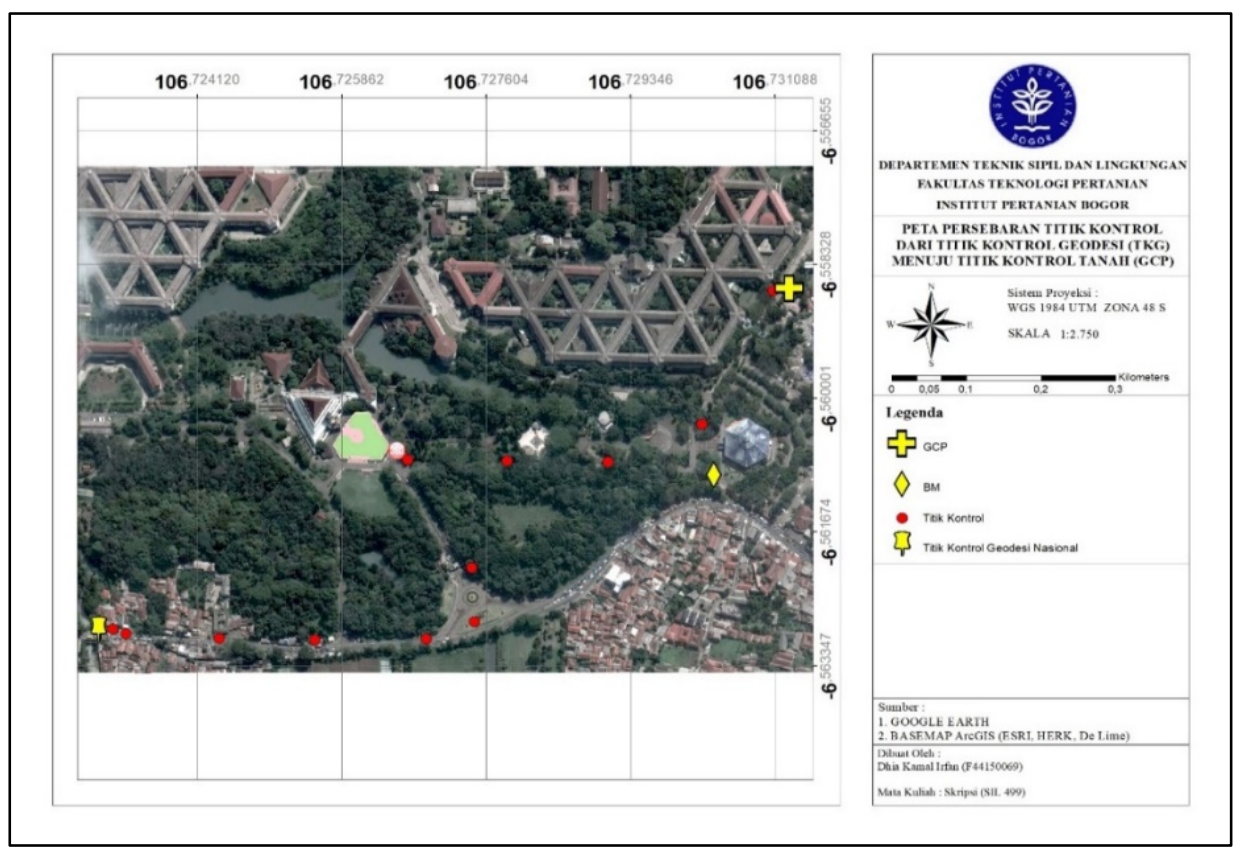

Gambar 2 Persebaran titik kontrol

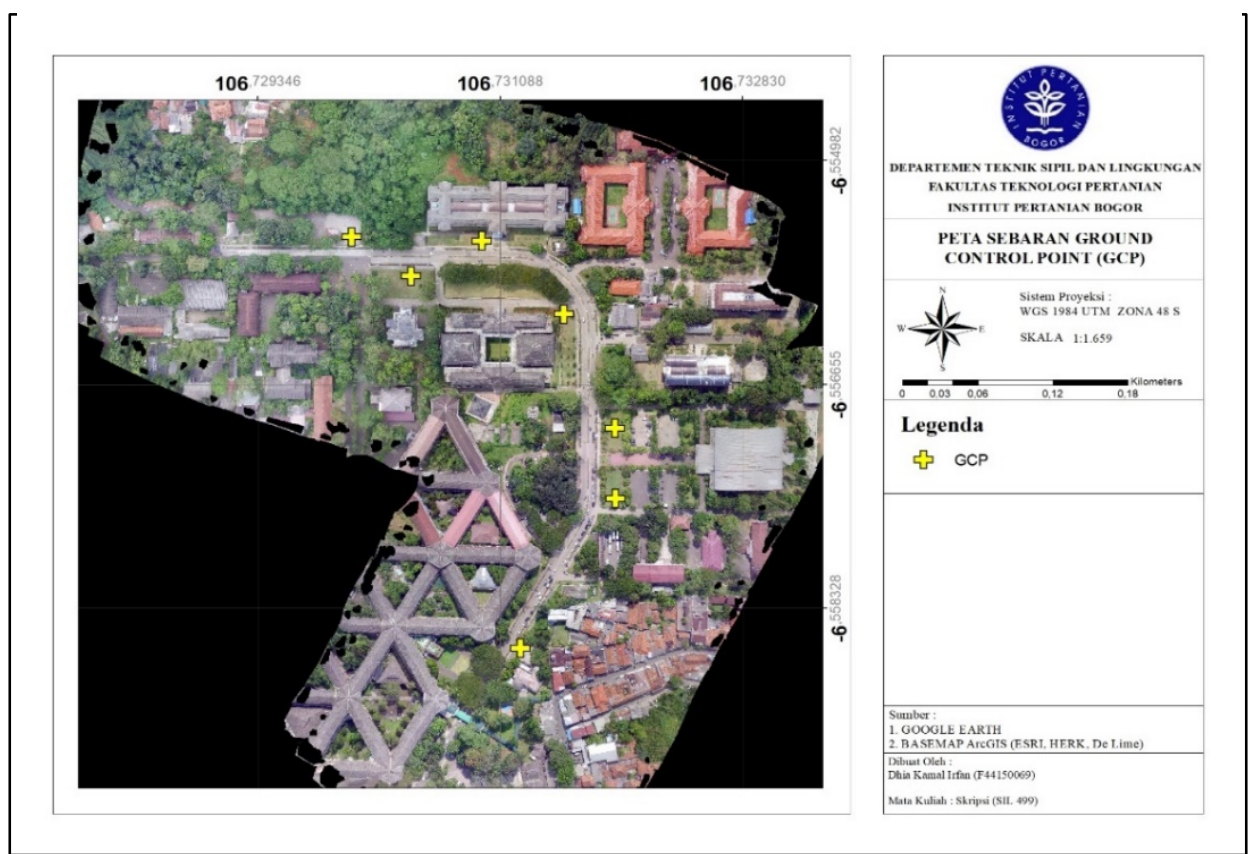

Gambar 3 Sebaran GCP 
Tabel 1 Detail titik kontrol geodesi nasional yang diacu

\begin{tabular}{|c|c|}
\hline ID Pilar & : JKH-g012 \\
\hline ID JKVN & : TTG.0400A \\
\hline Lintang & $: 6^{\circ} 33^{\prime} 46.50480^{\prime \prime} \mathrm{LS}$ \\
\hline Bujur & $: 106^{\circ} 43^{\prime} 22.46160^{\prime \prime} \mathrm{BT}$ \\
\hline Tinggi Elipsoid & $: 189.92$ \\
\hline Kondisi & : Baik \\
\hline $\begin{array}{l}\text { Waktu Pengukuran } \\
\text { Posisi Horizontal } \\
\text { Terakhir }\end{array}$ & $\begin{array}{l}: \text { Fri, 1 Jan } 2010 \\
\text { 00:00:00 GMT }\end{array}$ \\
\hline $\begin{array}{l}\text { Posisi Pengukuran } \\
\text { Tinggi } \\
\text { Orthometrik }\end{array}$ & $\begin{array}{l}\text { Pin/Brass tablet di atas } \\
\text { badan pilar }\end{array}$ \\
\hline Desa & : Babakan \\
\hline Kecamatan & : Dramaga \\
\hline Kabupaten & : Bogor \\
\hline Provinsi & : Jawa Barat \\
\hline Lokasi & : Babakan \\
\hline Pengelola Aset & $\begin{array}{lrl}: & \text { Badan } & \text { Informasi } \\
\text { Geospasial } & \end{array}$ \\
\hline Uraian Lokasi & $\begin{array}{l}\text { :Terletak di samping } \\
\text { jembatan Cihideung, } \\
\text { sebelah kiri jalan dari } \\
\text { Bogor-Pandeglang pada } \\
\text { Km 71,6 dari Jakarta } \\
\end{array}$ \\
\hline $\begin{array}{l}\text { Koordinat } \\
\text { Pendekatan }\end{array}$ & $:-6.56292106 .72291$ \\
\hline Catatan & $\begin{array}{l}\text { : Posisi horizontal dalam } \\
\text { SRGI } 2013\end{array}$ \\
\hline
\end{tabular}

Sumber : BIG (2019)

Dari Gambar 3 dapat dilihat persebaran GCP yang digunakan pada penelitian ini. Pada penelitian ini digunakan 7 GCP yang menyebar di sekitar lokasi penelitian. Penetapan GCP dilakukan dengan menentukan area terbuka yang dapat terlihat dari drone ketika dilakukan pengambilan foto udara. GCP yang berada pada lokasi dibuat dengan menggunakan kain berwarna jingga yang dibuat menyerupai bentuk silang atau $\mathrm{x}$ yang ditengahnya diberi selotip hitam. Penggunaan kain berwarna jingga ini dilakukan untuk mempermudah pencarian GCP pada hasil foto udara.
Sedangkan penggunaan selotip hitam berfungsi untuk menandai titik tengah dari kain tersebut dan juga menentukan titik dimana reflektor dan total station berdiri. Koordinat dari GCP yang digunakan pada penelitian ini dapat dilihat pada Tabel 2.

\section{Tabel 2 Koordinat GCP}

\begin{tabular}{cccc}
\hline \multirow{2}{*}{ No } & Nama & \multicolumn{2}{c}{ Koordinat } \\
\cline { 3 - 4 } & Titik & Bujur & Lintang \\
\hline \multirow{2}{*}{1} & GCP & $106^{\circ} 43^{\prime} 52.90^{\prime \prime}$ & $6^{\circ} 33^{\prime} 31.40^{\prime \prime}$ \\
& 1 & BT & LS \\
2 & GCP & $106^{\circ} 43^{\prime} 55.40^{\prime \prime}$ & $6^{\circ} 33^{\prime} 27.43^{\prime} \prime$ \\
& 2 & BT & LS \\
3 & GCP & $106^{\circ} 43^{\prime} 55.47^{\prime \prime}$ & $6^{\circ} 33^{\prime} 25.54^{\prime \prime}$ \\
& 3 & BT & LS \\
4 & GCP & $106^{\circ} 43^{\prime} 54.29^{\prime \prime}$ & $6^{\circ} 33^{\prime} 22.1^{\prime \prime}$ \\
& 4 & BT & LS \\
5 & GCP & $106^{\circ} 43^{\prime} 52.22^{\prime \prime}$ & $6^{\circ} 33^{\prime} 20.38^{\prime \prime}$ \\
& 5 & BT & LS \\
6 & GCP & $106^{\circ} 43^{\prime} 50.46^{\prime \prime}$ & $6^{\circ} 33^{\prime} 21.56^{\prime \prime}$ \\
& 6 & BT & LS \\
7 & GCP & $106^{\circ} 43^{\prime} 48.91^{\prime \prime}$ & $6^{\circ} 33^{\prime} 20.54^{\prime \prime}$ \\
& 7 & BT & LS \\
\hline
\end{tabular}

Posisi GCP berdasarkan nama yakni GCP 1 berada di depan gedung Fakultas Pertanian IPB, GCP 2 berada di sebelah barat daya gedung Gymnasium, GCP 3 berada di sebelah utara dari GCP 2, GCP 4 berada di timur gedeung CCR IPB, GCP 5 berada pada di sebelah selatan gedung Teaching Lab IPB, GCP 6 berada di depan gedung Tanoto IPB, dan GCP 7 berada di lahan parker di barat gedung Teaching Lab. Lokasi ini dipilih karena memiliki visibilitas yang baik ketika dilakukan pengambilan foto udara menggunakan drone. Koordinat drone sendiri memiliki error atau kesalahan baik pada vertikal maupun horizontal jika dibandingkan dengan koordinat GCP, kesalahan koordinat ini dapat dilihat pada Tabel 3 
JSIL | Irfan dkk. : Evaluasi Geometri jalan Menggunakan UAV Dengan Aplikasi Agisoft Photoscanner Pada Jalan Meranti Kampus IPB Dramaga

Tabel 3 Kesalahan koordinat drone terhadap GCP

\begin{tabular}{cccc}
\hline \multirow{2}{*}{ No } & \multirow{2}{*}{ Nama Titik } & \multicolumn{2}{c}{ Kesalahan Koordinat } \\
\cline { 3 - 4 } 1 & GCP 1 & 0,105310 & $-0,154440$ \\
2 & GCP 2 & $-0,328924$ & 0,510130 \\
3 & GCP 3 & $-0,361262$ & 0,572177 \\
4 & GCP 4 & $-0,232798$ & 0,374920 \\
5 & GCP 5 & 0,022701 & $-0,036193$ \\
6 & GCP 6 & 0,302871 & $-0,485029$ \\
7 & GCP 7 & 0,492102 & $-0,781565$ \\
& RMS Error & 0,301993 & 0,478008 \\
\hline
\end{tabular}

Dari Tabel 3 dapat dilihat kesalahan koordinat $\mathrm{Y}$ dan $\mathrm{X}$. Pada kesalahan koordinat $\mathrm{Y}$ nilai terbesar yang didapatkan yakni $0,492102 \mathrm{~m}$ dan terkecil 0,022701 m. Sedangkan untuk kesalahan koordinat $\mathrm{X}$ nilai terbesar yang didapatkan sebesar $-0,781565 \mathrm{~m}$ dan terkecil $-0,36193 \mathrm{~m}$. Sedangkan untuk RMSE dari koordinat Y sebesar
0,301993 $\mathrm{m}$ dan untuk koordinat $\mathrm{X}$ sebesar 0,478008 m. Nilai RMSE dapat terjadi karena konversi satuan koordinat dari derajat menjadi meter. Konversi ini dilakukan karena total station sebagai alat bantu untuk mencari koordinat yang peneliti pakai hanya menerima koordinat dengan satuan $m$ atau meter. Selain dari pengubahan koordinat besarnya nilai RMSE juga dapat terjadi karena kesalahan ketika melakukan input titik GCP pada saat pengolahan data.

Pembuatan atau perencanaan jalur terbang menggunakan aplikasi Pix4D, yang terpasang pada ponsel android. Aplikasi ini juga bisa menerbangkan drone secara otomatis sesuai dengan jalur yang telah dibuat sebelumnya. Penentuan jalur terbang dari drone ini dilakukan setelah melakukan penentuan GCP yang berada di sekitar lokasi penelitian. Jalur terbang dapat dilihat pada Gambar 4. Jalur terbang ini terbagi menjadi dua di karenakan geometri jalan yang berbelok $\pm 90^{\circ}$ sehingga dibutuhkan 2 jalur terbang.

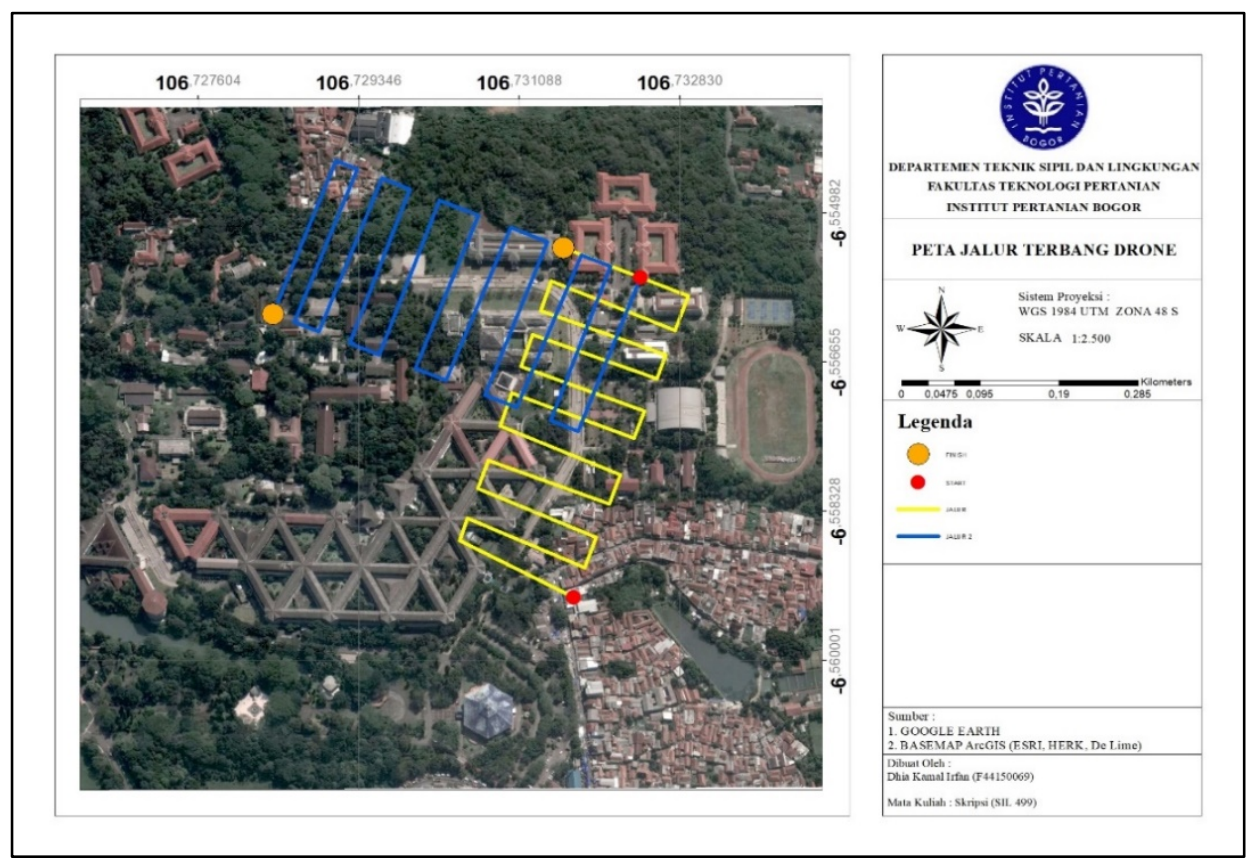

Gambar 4 Jalur terbang drone

Hasil orthophoto yang didapatkan setelah melakukan pengolahan data baik dengan koreksi GCP maupun tidak hasilnya tidak terlalu berbeda hanya 
sedikit bergeser sesuai dengan perbedaan koordinat hasil drone dengan GCP. Hasil orthophoto tanpa koreksi GCP dapat dilihat pada Gambar 5 dan dengan koreksi dapat dilihat pada Gambar 6 .
Secara visual, orthophoto yang dihasilkan memiliki tingkat detail yang bagus dan dapat digunakan untuk proses identifikasi objek apa saja yang terdapat pada lokasi penelitian secara jelas.

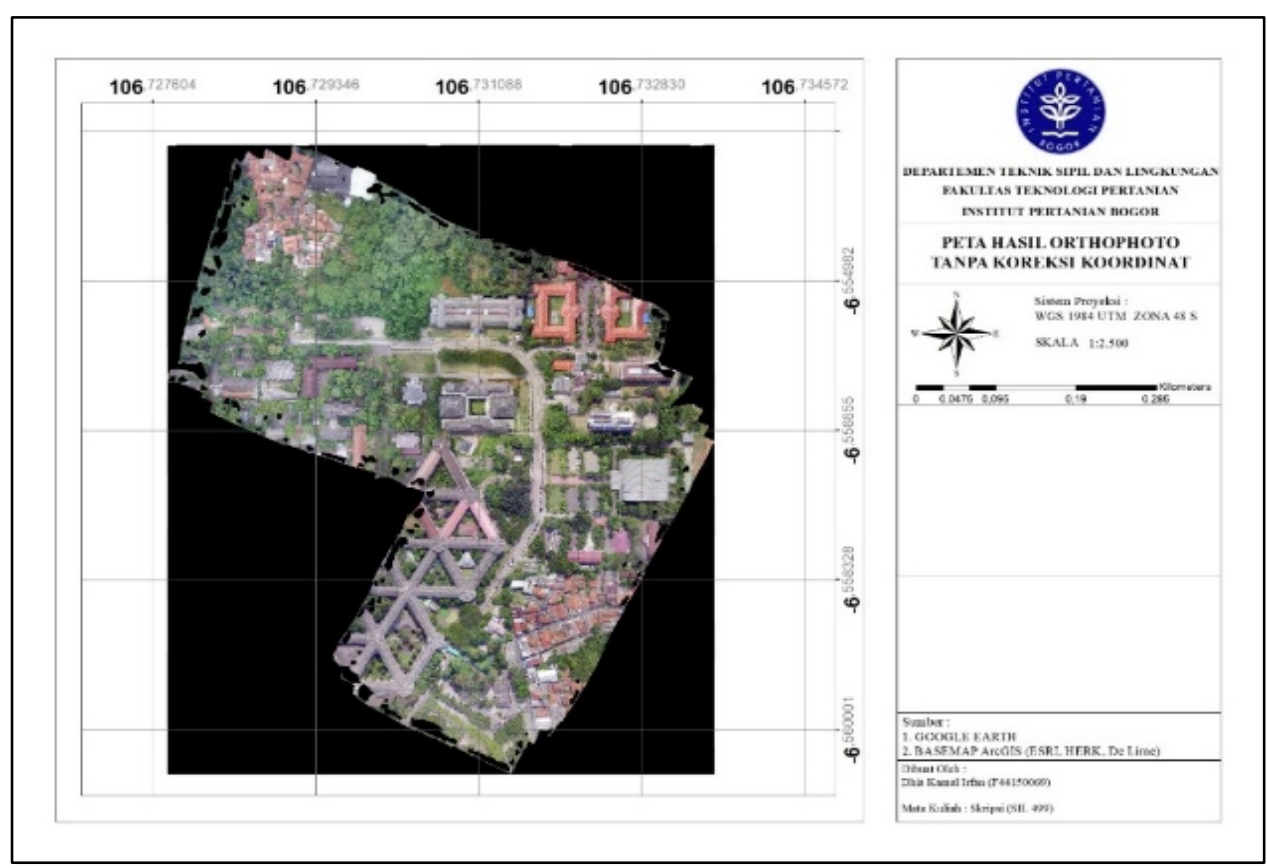

Gambar 5 Hasil orthophoto tanpa koreksi koordinat

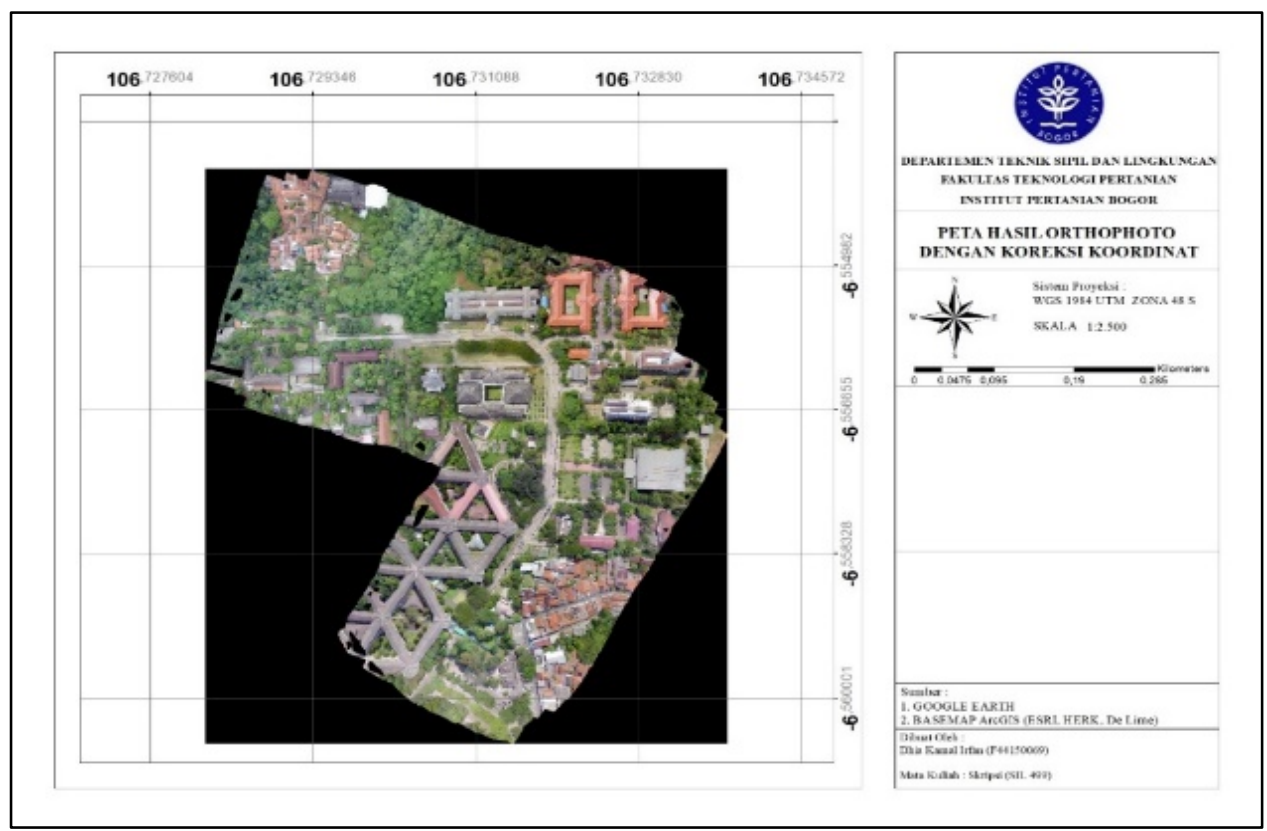

Gambar 6 Hasil orthophoto dengan koreksi koordinat 
JSIL | Irfan dkk. : Evaluasi Geometri jalan Menggunakan UAV Dengan Aplikasi Agisoft Photoscanner Pada Jalan Meranti Kampus IPB Dramaga

Peta RBI atau Rupabumi Indonesia sendiri memiliki standar ketelitian geometri yang diatur dalam Peraturan Kepala BIG No.15 Tahun 2004 (BIG 2014). Ketentuan ketelitian Geometri peta RBI dapat dilihat pada Tabel 4. Pada tabel tersebut dapat dilihat berapa nilai ketelitian yang sudah dikalikan dengan CE90 untuk RMSE horizontal dan LE90 untuk RMSE vertikal. CE90 atau circular error 90\% adalah ukuran ketelitian geometrik horizontal yang didefinisikan sebagai radius lingkaran yang menunjukkan bahwa $90 \%$ kesalahan atau perbedaan posisi horizontal objek di peta dengan posisi yang dianggap sebenarnya tidak lebih besar dari radius tersebut (BIG 2014).

Tabel 4 Ketentuan ketelitian geometri peta RBI

\begin{tabular}{cccccccccc}
\hline & & & \multicolumn{5}{c}{ Ketelitian Peta RBI } \\
\cline { 5 - 9 } No. & Skala & $\begin{array}{c}\text { Interval } \\
\text { kontur } \\
\end{array}$ & & \multicolumn{2}{c}{ Kelas 1} & \multicolumn{3}{c}{ Kelas 2 } & \multicolumn{3}{c}{ Kelas 3 } \\
\cline { 5 - 9 } & & & $\begin{array}{c}\text { Horizontal } \\
(\mathrm{m})\end{array}$ & $\begin{array}{c}\text { Vertikal } \\
(\mathrm{m})\end{array}$ & $\begin{array}{c}\text { Horizontal } \\
(\mathrm{m})\end{array}$ & $\begin{array}{c}\text { Vertikal } \\
(\mathrm{m})\end{array}$ & $\begin{array}{c}\text { Horizontal } \\
(\mathrm{m})\end{array}$ & $\begin{array}{c}\text { Vertikal } \\
(\mathrm{m})\end{array}$ \\
\hline 1 & $1: 1.000 .000$ & 400 & 200 & 200 & 300 & 300 & 500 & 500 \\
2 & $1: 500.000$ & 200 & 100 & 100 & 150 & 150 & 250 & 250 \\
3 & $1: 250.000$ & 100 & 50 & 50 & 75 & 75 & 125 & 125 \\
4 & $1: 100.000$ & 40 & 20 & 20 & 30 & 30 & 50 & 50 \\
5 & $1: 50.000$ & 20 & 10 & 10 & 15 & 15 & 25 & 25 \\
6 & $1: 25.000$ & 10 & 5 & 5 & 7,5 & 7,5 & 12,5 & 12,5 \\
7 & $1: 10.000$ & 4 & 2 & 2 & 3 & 3 & 5 & 5 \\
8 & $1: 5.000$ & 2 & 1 & 1 & 1,5 & 1,5 & 2,5 & 2,5 \\
9 & $1: 2.500$ & 1 & 0,5 & 0,5 & 0,75 & 0,75 & 1,25 & 1,25 \\
10 & $1: 1.000$ & 0,4 & 0,2 & 0,2 & 0,3 & 0,3 & 0,5 & 0,5 \\
\hline
\end{tabular}

RMSEr pada penelitian ini didapatkan sebesar $0,5654 \mathrm{~m}$. Ketelitian dari peta yang dihasilkan adalah sebesar $0,858 \mathrm{~m}$. Jika dihubungkan dengan tabel 4 maka peta orthophoto atau RBI yang dihasilkan dengan skala 1:2.500 termasuk dalam ketelitian horizontal kelas 3. Hal tersebut menunjukkan bahwa sedikitnya 90\% kesalahan atau pergeseran posisi objek pada peta RBI skala 1:2.500 tersebut tidak lebih dari 1,25 meter untuk posisi horizontal.

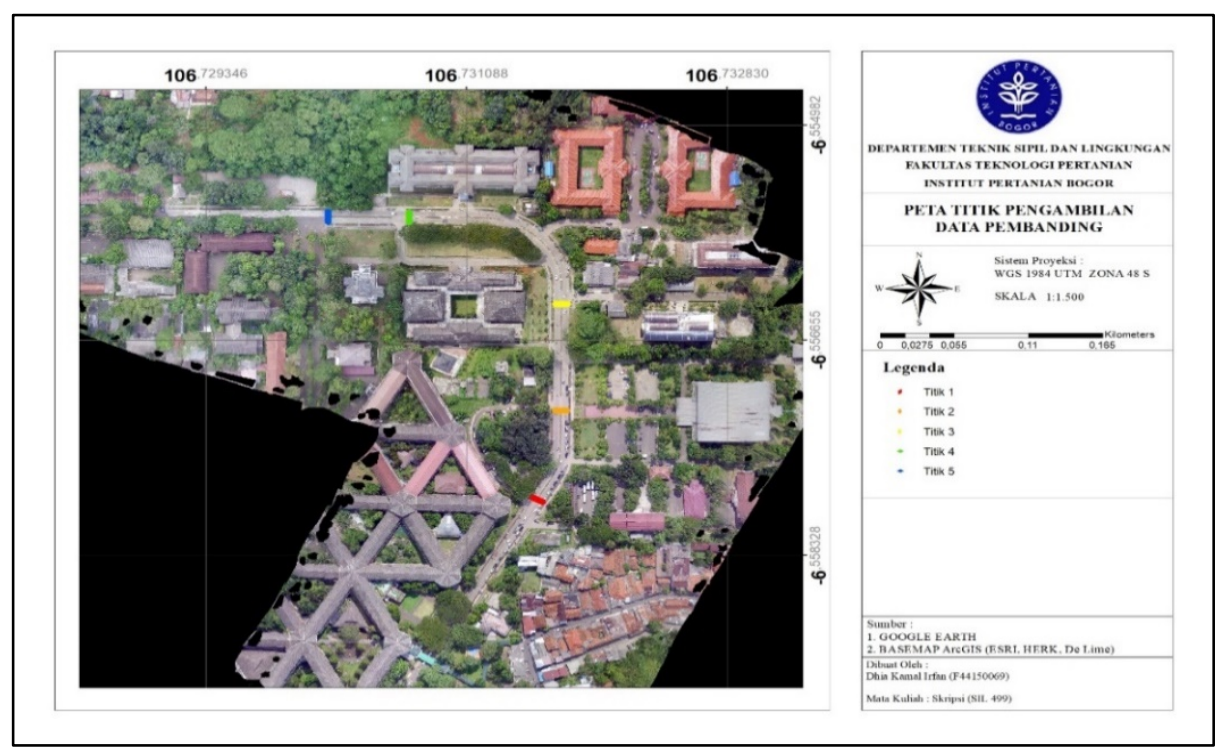

Gambar 7 Persebaran titik pengambilan data pembanding 
Perbedaan yang terjadi dikarenakan adanya koreksi koordinat dari drone menggunakan GCP. Dalam penelitian ini dibutuhkan data pembanding yang dianggap benar serta ideal. Data pembanding yang dimaksudkan adalah profil melintang atau lebar jalan dari beberapa titik yang tersebar pada lokasi penelitian. Terdapat 5 titik yang digunakan untuk data pembanding ditentukan dengan pertimbangan visibilitas dan kemudahan dalam pengambilan data. Titik pengambilan data pembanding yang berupa profil melintang dapat dilihat pada Gambar 7.

Titik data pembanding yang sudah ditentukan memiliki hasil berupa lebar jalan atau profil melintang. Pengambilan data ini dilakukan dengan mengukur lebar jalan yang ada dengan meteran gulung. Hasil dari pengukuran ini kemudian dibandingkan dengan hasil orthophoto yang ada. Hasil orthophoto yang dibandingkan ialah keduanya baik dengan koreksi koordinat menggunakan GCP dan yang tidak dengan koreksi koordinat, sehingga ketiganya memiliki hasil profil melintang atau lebar jalan masing masing. Hasil tersebut dapat dilihat pada Tabel 5.

Tabel 5 Perbandingan hasil pengukuran profil melintang jalan

\begin{tabular}{ccccc}
\hline & & \multicolumn{3}{c}{ Hasil Pengukuran (m) } \\
\cline { 3 - 5 } No & $\begin{array}{c}\text { Nama } \\
\text { Titik }\end{array}$ & $\begin{array}{c}\text { Lang } \\
\text { sung }\end{array}$ & $\begin{array}{c}\text { Orthophoto } \\
\text { tanpa } \\
\text { koreksi } \\
\text { koordinat }\end{array}$ & $\begin{array}{c}\text { Orthophoto } \\
\text { dengan } \\
\text { koreksi } \\
\text { koordinat }\end{array}$ \\
\hline 1 & Titik 1 & 11,03 & 11,08502 & 11,07950 \\
2 & Titik 2 & 11,07 & 11,05339 & 11,04433 \\
3 & Titik 3 & 11,02 & 11,22287 & 11,21502 \\
4 & Titik 4 & 11,02 & 11,49151 & 10,73698 \\
5 & Titik 5 & 11,02 & 11,67840 & 10,63321 \\
\hline
\end{tabular}

Terlihat pada tabel 5 ketiga hasil pengukuran memiliki nilai yang berbeda beda. Hasil pengukuran dari orthophoto dilakukan dengan menggunakan alat bantu berupa software AutoCAD 2017. Hasil pengukuran orthophoto tanpa koreksi koordinat memiliki selisih terkecil atau perbedaan terkecil dengan pengukuran langsung adalah sebesar $0,01661 \mathrm{~m}$ yang didapatkan dari titik 2 , sedangkan untuk hasil orthophoto dengan koreksi koordinat memiliki selisih terkecil atau perbedaan terkecil dengan pengukuran langsung sebesar $0,02567 \mathrm{~m}$ yang didapatkan dari titik 2 . Selisih terbesar atau perbedaan terbesar untuk dua hasil orthophoto didapatkan pada titik 5, untuk hasil orthophoto tanpa koreksi koordinat memiliki nilai sebesar 0,6584 $\mathrm{m}$ dan hasil orthophoto dengan koreksi koordinat memiliki nilai sebesar 0,38679 m.

Rata - rata perbedaan untuk hasil orthophoto tanpa koordinat memiliki nilai sebesar $0,281 \mathrm{~m}$ dan hasil orthophoto dengan koreksi koordinat sebesar $0,188 \mathrm{~m}$. Dari kedua rata - rata ini dapat dihasilkan nilai akurasi dari masing masing hasil orthophoto berdasarkan profil melintang atau lebar jalan. Hasil orthophoto tanpa koreksi koordinat memiliki nilai akurasi sebesar $97,453 \%$ dan hasil orthophoto dengan koreksi koordinat memiliki nilai akurasi sebesar 98,296\%. Nilai akurasi yang didapatkan dari kedua hasil orthophoto ini sangat baik, karena nilainya masih diatas $90 \%$ atau memiliki nilai selisih lebar jalan \pm 1 meter. Data elevasi titik uji yang diambil dapat dilihat pada Tabel 6. 
JSIL I Irfan dkk. : Evaluasi Geametri jalan Menggunakan UAV Dengan Aplikasi Agisoft Phatoscanner Pada Jalan Meranti Kampus IPB Dramaga

Tabel 6 Data elevasi titik uji

\begin{tabular}{cccc}
\hline & & \multicolumn{2}{c}{ Elevasi (mdpl) } \\
\cline { 3 - 4 } No. & $\begin{array}{c}\text { Nama } \\
\text { Titik }\end{array}$ & $\begin{array}{c}\text { Tanpa } \\
\text { koreksi } \\
\text { elevasi }\end{array}$ & $\begin{array}{c}\text { Dengan } \\
\text { koreksi elevasi }\end{array}$ \\
\hline 1 & 1.1 & 195,601776 & 255,060532 \\
2 & 1.2 & 195,413300 & 254,730225 \\
3 & 1.3 & 195,513433 & 254,900742 \\
4 & 2.1 & 204,054947 & 258,748322 \\
5 & 2.2 & 204,054855 & 258,474670 \\
6 & 2.3 & 203,994110 & 258,414795 \\
7 & 3.1 & 207,179199 & 258,352631 \\
8 & 3.2 & 207,123672 & 258,287451 \\
9 & 3.3 & 206,923431 & 258,582581 \\
10 & 4.1 & 206,980621 & 257,234528 \\
11 & 4.2 & 206,890472 & 257,374237 \\
12 & 4.3 & 206,697845 & 257,412292 \\
13 & 5.1 & 198,037872 & 255,430695 \\
14 & 5.2 & 198,159409 & 255,548813 \\
15 & 5.3 & 198,022308 & 255,263412 \\
\hline
\end{tabular}

Data elevasi tertinggi untuk hasil elevasi tanpa koreksi elevasi pada tabel 6 berada pada titik 3 di bagian kiri jalan yang bernilai 207,179199 mdpl, sedangkan data terendah berada pada titik 1 di bagian tengah jalan yang bernilai 195,41330 mdpl. Elevasi tertinggi pada hasil dengan koreksi koordinat berada pada titik 2 di bagian kiri jalan dengan nilai 258,748322 mdpl sedangkan nilai elevasi terendah berada sama dengan hasil tanpa koreksi koordinat yaitu pada titik 1 di bagian tengah jalan yang bernilai 254,730225 mdpl. Untuk perbandingan elevasi dari kedua hasil tersebut dapat dilihat pada Gambar 8.

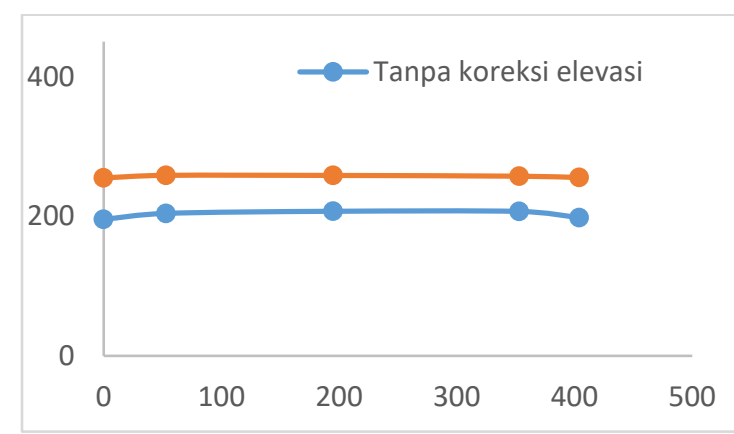

Gambar 8 Grafik perbedaan elevasi
Gambar diatas merupakan grafik yang berisikan data rata - rata elevasi di setiap titik yang kemudian di plot pada grafik. Sumbu $\mathrm{x}$ dari grafik tersebut berisikan jarak dari titik 1 hingga titik 5 sedangkan sumbu y berisikan elevasi dari kedua hasil yakni elevasi tanpa koreksi koordinat dan elevasi dengan koreksi koordinat. Grafik hasil dengan koreksi elevasi memiliki nilai yang elevasi yang tidak jauh berbeda antar titiknya jika dibandingkan dengan hasil tanpa koreksi elevasi yang memiliki perbedaan elevasi yang cukup tinggi yakni antara titik 1 dengan titik 2 dan antara titik 4 dengan titik 5. Gambar diatas dapat disebut juga alinyemen vertikal dari Jalan Meranti Kampus IPB Dramaga karena berisikan data elevasi yang dibandingkan dengan jarak atau panjang dari jalan tersebut. Kedua hasil tersebut memiliki perbedaan elevasi \pm 50 meter.

\section{Alinyemen Horizontal}

Perencanaan geometrik jalan memfokuskan pada pemilihan letak dan panjang dari bagian-bagian alinyemen horizontal, sesuai dengan kondisi medan sehingga terpenuhi kebutuhan akan pengoperasian lalu lintas, dan keamanan (ditinjau dari jarak pandangan dan sifat mengemudikan kendaraan di tikungan) (Sukirman 1994). Parameter yang dievaluasi pada alinyemen horizontal pada penelitian ini berupa parameter yang bisa dilihat secara visual dari hasil pengolahan data sebelumnya. Parameter yang dibahas adalah sudut belokan, radius belokan, dan panjang belokan. Keempat parameter tersebut dapat dilihat pada Tabel 7. 
Tabel 7 Hasil analisis alinyemen horizontal

\begin{tabular}{cccc}
\hline & & \multicolumn{2}{c}{ Nilai } \\
\cline { 3 - 4 } No. & Parameter & $\begin{array}{c}\text { Tanpa } \\
\text { koreksi }\end{array}$ & $\begin{array}{c}\text { Dengan } \\
\text { koreksi }\end{array}$ \\
\hline 1 & $\begin{array}{c}\text { Sudut belokan } \\
\text { pertama }\end{array}$ & $149^{\circ}$ & $150^{\circ}$ \\
2 & $\begin{array}{c}\text { Sudut belokan } \\
\text { kedua }\end{array}$ & $90^{\circ}$ & $88^{\circ}$ \\
3 & $\begin{array}{c}\text { Radius belokan } \\
\text { pertama }\end{array}$ & $40,61 \mathrm{~m}$ & $30,81 \mathrm{~m}$ \\
4 & $\begin{array}{c}\text { Radius belokan } \\
\text { kedua }\end{array}$ & $53,75 \mathrm{~m}$ & $49,34 \mathrm{~m}$ \\
5 & $\begin{array}{c}\text { Panjang } \\
\text { belokan/ busur } \\
\text { lingkaran } \\
\text { Panjang }\end{array}$ & $23,39 \mathrm{~m}$ & $21,39 \mathrm{~m}$ \\
6 & $\begin{array}{c}\text { belokan/ busur } \\
\text { lingkaran }\end{array}$ & $90,71 \mathrm{~m}$ & $89,3 \mathrm{~m}$ \\
\hline
\end{tabular}

Pada lokasi penelitian terdapat dua belokan yang termasuk dalam lokasi penelitian. Dua belok ini merupakan dasar dari penentuan hasil dari parameter yang didapatkan pada Tabel 13. Kedua belokan tersebut dapat diihat pada Gambar 9. Gambar tersebut menjelaskan lokasi dari kedua belokan, belokan yang berada di dalam lingkaran merah merupakan belokan pertama dan belokan yang berada di dalam lingkaran berwarna kuning merupakan belokan kedua.

Parameter parameter yang telah didapatkan disusun menjadi sebuah diagram belokan. Diagram tersebut berisikan informasi dari alinyemen horizontal. Dua belokan yang terdapat pada penelitian ini termasuk ke dalam belokan full circle, hal ini didapatkan setelah dilakukan analisis bentuk belokan. Diagram full circle berisikan informasi berupa panjang busur lingkaran atau Lc, radius belokan atau r, sudut belokan atau $\alpha$, tangen lingkaran atau Tc, dan jarak titik persimpangan ke lengkung peralihan atau Et.

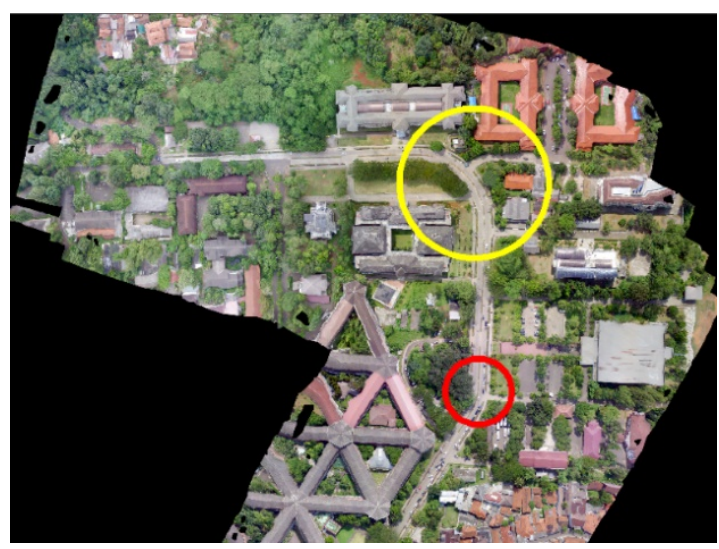

Gambar 9 Belokan pada lokasi penelitian

Gambar 10 merupakan diagram dari belokan 1 dari diagram tersebut dapat dilihat beberapa nilai yang terdapat dalam gambar tersebut. Radius belokan atau $\mathrm{r}$ dari belokan 1 memiliki nilai sebesar 49,3 m. Panjang busur lingkaran atau Lc dari belokan tersebut memiliki nilai $24,7 \mathrm{~m}$. Tangen dari lingkaran atau Tc belokan 1 memiliki nilai sebesar 12,7 m. Sudut belokan atau $\alpha$ dari belokan 1 memiliki nilai $31^{\circ}$. Jarak titik persimpangan ke lengkung peralihan atau Et pada belokan tersebut memiliki nilai $1,7 \mathrm{~m}$.

Gambar 11 merupakan diagram dari belokan 2 dari diagram tersebut dapat dilihat beberapa nilai yang terdapat dalam gambar tersebut.

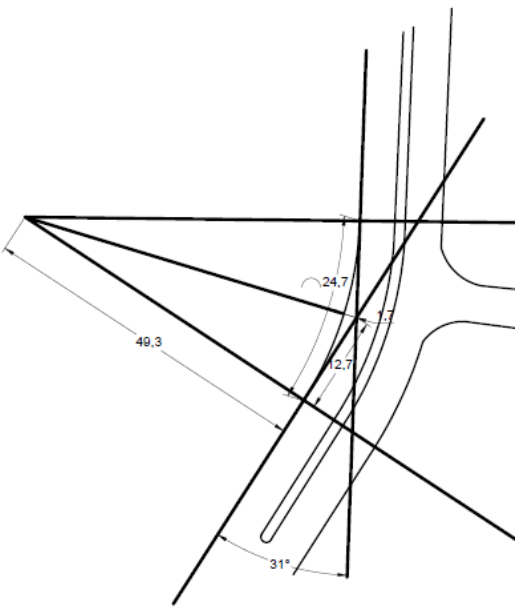

Gambar 10 Diagram belokan 1 
Radius belokan atau r dari belokan 2 memiliki nilai sebesar 52,7 m. Panjang busur lingkaran atau Lc dari belokan tersebut memiliki nilai $83,4 \mathrm{~m}$. Tangen dari lingkaran atau Tc belokan 1 memiliki nilai sebesar $55 \mathrm{~m}$. Sudut belokan atau $\alpha$ dari belokan 1 memiliki nilai $92^{\circ}$.

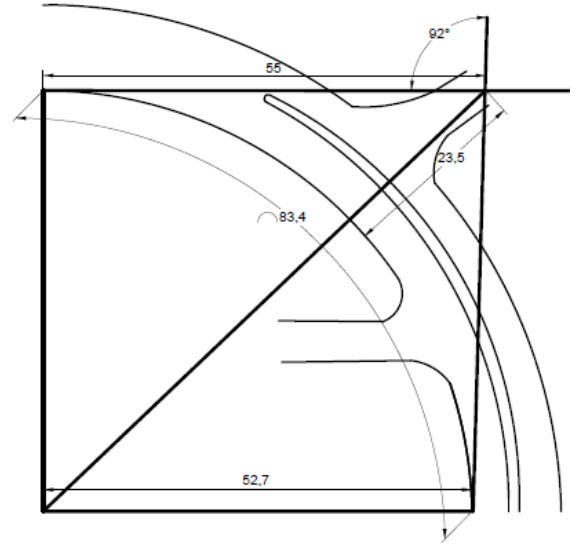

Gambar 11 Diagram belokan 2

Jarak titik persimpangan ke lengkung peralihan atau Et pada belokan tersebut memiliki nilai $23,5 \mathrm{~m}$. Pembuatan diagram belokan ini sesuai dengan peraturan Direktorat Jenderal Bina Marga No. 038/TBM/1997 (DirjenBM 1997). Kedua diagram tersebut memiliki beberapa nilai yang tidak terdapat dalam parameter yakni nilai tangen dari lingkaran Tc dan jarak dari titik persimpangan ke lengkung peralihan atau Et.

\section{Alinyemen Vertikal}

Alinyemen vertikal adalah perencanaan elevasi sumbu jalan pada setiap titik yang ditinjau, berupa profil memanjang. Pada peencanaan alinyemen vertikal terdapat kelandaian positif (tanjakan) dan kelandaian negatif (turunan), sehingga kombinasinya berupa lengkung cembung dan lengkung cekung. Disamping kedua lengkung tersebut terdapat pula milai kelandaian nol (datar) (DirjenBM 1997). Parameter yang diukur pada alinyemen vertikal yaitu nilai kelandaian dan panjang lengkung vertikal (Ls).

Pada penelitian ini dibahas dua titik evaluasi alinyemen vertikal yakni di bagian awal lokasi penelitian dan di akhir lokasi penelitian. Dua titik ini dipilih karena memiliki beda elevasi yang cukup signifikan yakni sebesar 3,648 $\mathrm{m}$ dan 1,926 m untuk elevasi dengan koreksi, sedangkan nilai beda elevasi tanpa koreksi sebesar 8,525 $\mathrm{m}$ dan 8,783 $\mathrm{m}$.

\section{KESIMPULAN}

Evaluasi geometri jalan menggunakan UAV dapat dilakukan, terhadap dua unsur geometri jalan berupa alinyemen horizontal berupa profil melintang jalan dan alinyemen vertikal dari Jalan Meranti Kampus IPB Dramaga. Penelitian ini menghasilkan akurasi pengukuran profil melintang jalan sebesar 97,243\% dan 98,296\% untuk hasil orthophoto tanpa dan dengan koreksi koordinat serta menggunakan GCP.

Parameter alinyemen horizontal berupa sudut belokan, radius belokan, dan panjang belokan, terdapat dua belokan yang di analisis dengan nilai masing masing parameter setiap belokan secara berturut untuk data tanpa koreksi koordinat dan elevasi adalah $149^{\circ} ; 90^{\circ}$; 40,61 m; 53,75 m; 23,39 m; 90,71 m. Hasil analisis alinyemen horizontal untuk data dengan koreksi koordinat adalah $150^{\circ} ; 88^{\circ} ; 30,81 \mathrm{~m} ; 49,34 \mathrm{~m}$; $21,39 \mathrm{~m} ; 89,3 \mathrm{~m}$. Alinyemen vertikal mencakup parameter yakni panjang lengkung vertikal dan kelandaian, dengan hasil analisis untuk kedua parameter dari dua titik adalah $16,08 \%$, $17,22 \%, 53 \mathrm{~m}$, dan $51 \mathrm{~m}$ untuk hasil tanpa koreksi koordinat dan elevasi sedangkan untuk hasil dengan koreksi koordinat dan elevasi sebesar 6,88\%, $3,77 \%, 53 \mathrm{~m}$, dan $51 \mathrm{~m}$. 


\section{DAFTAR PUSTAKA}

[Dirjen BM] Direktorat Jendral Bina Marga. 1997. Jalan. Tata Cara Perencanaan Geometrik Jalan Antar Kota. Peraturan Direktorat Jenderal Bina Marga No. 038/TBM/1997. Jakarta (ID) : Direktorat Jenderal Bina Marga Departemen Pekerjaan Umum.

Gunawan MA, Afifuddin IAM. 2014.

Critical succes factors pelaksanaan proyek konstruksi jalan dan jembatan di kabupaten Pidie Jaya. Jurnal Teknik Sipil Pascasarjana Universitas Syiah Kuala. 3(1):15-25.

Koloway BS. 2009. Kinerja ruas jalan perkotaan jalan Prof. Dr. Satrio. DKI Jakarta. Jurnal Perencanaan Wilayah dan Kota. 20 (3) : 215 230.

Nugroho ASB. 2016. Kajian Pemanfaatan Drone Untuk Pekerjaan Pengawasan Konstruksi [Skripsi]. Yogyakarta (ID): Universitas Atma Jaya Yogyakarta.

Sukirman S. 1994. Dasar-Dasar Perencanaan Geometrik Jalan. Bandung (ID): Nova 
JSIL | Irfan dkk. : Evaluasi Geametri jalan Menggunakan UAV Dengan Aplikasi Agisaft Phatoscanner Pada Jalan Meranti Kampus IPB Dramaga 